\title{
COX-2 expression is associated with an aggressive phenotype in ductal carcinoma in situ
}

\author{
GP Boland', IS Butt', R Prasad', WF Knox ${ }^{2}$ and NJ Bundred*,I \\ 'Academic Department of Surgery, University Hospital of South Manchester, Southmoor Road, Manchester M23 9LT, UK; ${ }^{2}$ Department of Pathology, \\ University Hospital of South Manchester, Southmoor Road, Manchester M23 9LT, UK
}

\begin{abstract}
Cyclooxygenase type-2 (COX-2) is overexpressed in malignant tumours including breast cancers, though the mechanism of upregulation is unclear. This study aimed to determine COX-2 expression in ductal carcinoma in situ (DCIS) in comparison to invasive breast cancer (IBC) and normal breast, and also to investigate the relationship of COX-2 expression with HER-2 expression, oestrogen receptor (ER), tumour grade and cellular proliferation (Ki67) in DCIS. Cyclooxygenase type-2, HER-2, ER and Ki67 expression were determined by immunohistochemistry on paraffin tissue sections of DCIS $(n=187)$, IBC $(n=65)$ and normal breast reduction tissue $(n=60)$. Cyclooxygenase type-2 expression in DCIS $(67 \%, P<0.00 \mathrm{I})$ and IBC $(63 \%, P<0.00 \mathrm{I})$ was significantly greater than in normal breast (23\%). There was no difference in COX-2 expression level between DCIS and IBC $(P=0.87)$ or between normal breast from reduction mammoplasty tissue and normal breast ducts around DCIS $(22 \%, P=0.29)$. In DCIS, COX-2 expression was associated with higher cellular proliferation rates $(P<0.000 \mathrm{I})$, nuclear grade $(P=0.003)$, with ER negativity $(P=0.003)$ and with HER-2 positivity $(P<0.000 \mathrm{I})$. Cyclooxygenase type-2 expression is upregulated in in situ breast cancer and is associated with surrogate markers of an aggressive DCIS phenotype including nonoestrogen-regulated signalling pathways. Cyclooxygenase type-2 inhibition may potentially prevent the development of ER-positive and ER-negative breast cancers. British Journal of Cancer (2004) 90, 423-429. doi:I0.1038/sj.bjc.660I534 www.bjcancer.com (C) 2004 Cancer Research UK
\end{abstract}

Keywords: DCIS; Breast; COX-2; HER-2; oestrogen; proliferation

Cyclooxygenase type-2 (COX-2) is overexpressed in many human malignant tumours (Sano et al, 1995; Wolff et al, 1998; Mohammed et al, 1999; Tucker et al, 1999; Soslow et al, 2000) and has been linked to the process of carcinogenesis (Liu et al, 2001), tumour survival (Tsujii et al, 1998), invasion (Tsujii et al, 1997) and metastasis (Tsujii and DuBois, 1995; Costa et al, 2002). Epidemiological studies have reported a significant reduction in the incidence of human gastro-intestinal cancers with COX inhibition by NSAIDS (Shaheen et al, 2002). Although the evidence for breast cancer prevention is less strong, a recent meta-analysis of 14 studies (six cohort, eight case-controlled) gave a combined estimate of a reduced relative risk of 0.82 ( $95 \%$ confidence interval $0.75-0.89$ ) with regular NSAID use (Khuder and Mutgi, 2001), but this provided no data on the dose-response effect for NSAID type or duration of use.

Pharmacological studies with selective COX-2 inhibitors in animal models of breast cancer (and other cancers) have consistently demonstrated a dose-dependent arrest of tumour growth, invasion and metastasis (Alshafie et al, 2000; Harris et al,

*Correspondence: Professor NJ Bundred; E-mail: bundredn@.man.ac.uk An abstract of this paper was presented at the British Association of Surgical Oncologists (Glasgow, UK, November 200I) at the Society for Academic Research in Surgery (London, UK, January 2002) and by poster presentation at the 25th Annual breast cancer symposium (San Antonio, TX, USA, December 2002).

Received 20 May 2003; revised 13 October 2003; accepted 5 November 2003
2000; Rozic et al, 2001; Kundu and Fulton, 2002). These epidemiological and animal data indicate the potential of longterm COX-2 inhibition by the safer new generation of COX-2specific NSAIDS for breast cancer chemoprevention.

Early studies of COX-2 RNA/protein expression in invasive breast cancer (IBC) yielded inconsistent findings, with expression reported to be between 0 and $100 \%$ of samples (Parrett et al, 1997; Hwang et al, 1998). Immunohistochemical studies of COX-2 antigen expression in IBC have produced more consistent findings, with moderate or strong levels of COX-2 expression found in 36$56 \%$ of IBCs (Soslow et al, 2000; Half et al, 2002; Ristimaki et al, 2002; Denkert et al, 2003; Spizzo et al, 2003; Watanabe et al, 2003), with COX-2 expression predicting poorer disease-free survival (Ristimaki et al, 2002; Denkert et al, 2003; Spizzo et al, 2003).

COX-2 upregulation appears to occur early in the process of carcinogenesis, with overexpression reported in a number of premalignant lesions and in in situ neoplasia of nonbreast glandular epithelium (Eberhart et al, 1994; Kirschenbaum et al, 2000; Shirahama, 2000; Morris et al, 2001). To date, there are few reports of COX-2 expression in ductal carcinoma in situ (DCIS) of the breast. These have been limited to DCIS surrounding invasive cancer (Soslow et al, 2000; Half et al, 2002), with only two studies in primary DCIS (Shim et al, 2003; Watanabe et al, 2003). All these studies have looked at less than 50 DCIS tumours, and have shown moderate or strong COX-2 antigen expression in $60-85 \%$ of lesions. Shim et al (2003) reported a correlation of COX-2 expression and nuclear grade in pure DCIS, although the study lacked power to demonstrate an association with other markers (Shim et al, 2003). No single study has yet specifically determined 
COX-2 expression in pure DCIS compared to invasive cancer and normal breast epithelium (from breast reduction tissue) and the relationship to surrogate molecular markers of pathways driving cell proliferation in DCIS.

Despite the data on elevated COX-2 expression in breast neoplasia, the mechanism of upregulation remains unclear. In this study, we evaluated COX-2 expression in DCIS using immunohistochemistry in comparison to expression in invasive cancer and normal breast, and investigated the association between COX-2 expression and cellular proliferation, nuclear grade and HER-2 antigen expression in DCIS, since HER-2 is overexpressed in at least two-thirds of in situ breast cancer (Allred et al, 1993; Bobrow et al, 1995; Suo et al, 2001).

\section{PATIENTS AND METHODS}

\section{Tissue specimens and selection}

A retrospective study was performed on archival paraffinembedded formalin-fixed tissue samples of normal breast (reduction mammoplasty, $n=60)$, DCIS $(n=187)$ and IBC $(n=65)$ from women who had undergone surgery at the University Hospital of South Manchester. Antigen expression was assessed by immunohistochemistry. Samples were deliberately selected to include a higher proportion of HER-2-positive invasive cancer and a lower proportion of HER-2-negative DCIS than expected by random selection, to compare COX-2 expression in HER-2-expressing/ nonexpressing tumours.

\section{Immunohistochemistry (Figure 3)}

An immunohistochemical assay of COX-2, Ki67, oestrogen receptor (ER) and HER-2 was performed on paraffin wax sections (3-5 $\mu \mathrm{m}$ thick) of each tissue were mounted on APES (3aminopropyltriethoxysilane, Sigma) coated slides, de-waxed in xylene and rehydrated prior to immunohistochemical staining. Established protocols developed at the clinical research laboratory, Paterson Institute for Cancer Research, Manchester (a UK reference laboratory for HER-2 immunohistochemical staining) were followed for each antigen (except COX-2); these have been shown to produce reproducible immunostaining in DCIS (Gandhi et al, 2000; Dowsett et al, 2001). For all molecular markers, antigen retrieval was achieved by the pressure cooking method for $4 \mathrm{~min}$ in citrate buffer $(\mathrm{pH}=6.0)$.

For COX-2 expression, a primary goat polyclonal anti-human COX-2 antibody was used (sc-1745; Santa Cruz Biotechnology, USA) as described in other studies assessing COX-2 expression by immunohistochemistry (Komhoff et al, 2000; Shirahama, 2000; Cianchi et al, 2001; Sales et al, 2001; Shirahama et al, 2001; Hasturk et al, 2002; Muller-Decker et al, 2002) at a dilution of $1: 100$ for $1 \mathrm{~h}$, followed by a biotinylated rabbit anti-goat secondary antibody (DAKO, Z259) diluted 1:200 for $40 \mathrm{~min}$. Cyclooxygenase type-2 immunoreactivity was confirmed with another COX-2 primary antibody (Cayman Chemical Company, Ann Arbor, MI, USA, 160112 ) in 50 DCIS sections. For Ki67 (MIB-1), a primary mouse monoclonal antibody to MIB-1 was used (DAKO Ltd, UK, M7240) at $1: 50$ for $1 \mathrm{~h}$, followed by a biotinylated goat anti-mouse secondary antibody (DAKO Ltd, UK, E432) diluted $1: 200$ for $40 \mathrm{~min}$. For ER, a primary mouse anti-human ER antibody was used (DAKO Ltd, UK, M7047), at 1:33 for $1 \mathrm{~h}$, followed by a biotinylated secondary goat anti-mouse antibody (DAKO Ltd, UK, E432), at 1:200 for $40 \mathrm{~min}$. For HER-2 labelling, a primary mouse anti-human HER-2 antibody was used (DAKO Ltd, UK, A485) at $1: 40$ for $1 \mathrm{~h}$, followed by a biotinylated secondary rabbit antimouse antibody (DAKO Ltd, UK, E413), at a 1:200 for $40 \mathrm{~min}$. Antigen visualisation was achieved by applying a standard streptavidin-biotin complex (ABC, Vector labs, UK, PK-6100) for $30 \mathrm{~min}$ followed by diaminobenzidene chromogen (DAB, DAKO, UK) in $0.1 \% \mathrm{H}_{2} \mathrm{O}_{2}$ PBS solution. Sections were counterstained with Gill's haematoxylin.

A positive and negative control slide was included in each immunohistochemical assay. The positive controls used were as follows: COX-2 expression: high-grade transitional carcinoma of the urinary bladder and skin (Mohammed et al, 1999; Komhoff et al, 2000; Ristimaki et al, 2001); HER-2 expression: strongly HER2-positive $(3+)$ IBC; ER, PR and Ki67 expression: DCIS known to express the appropriate antigen as determined in previous studies of DCIS in our department. For negative controls, the appropriate primary antibody was omitted and either PBS or an iso-type matched IgG serum was applied. A specific COX-2 blocking peptide (Cayman Chemical Company, Ann Arbor, MI, USA, 360107) was used as a negative control in 50 DCIS sections stained with the Cayman anti-COX-2 antibody (160112) as previously described (Half et al, 2002).

\section{Evaluation of immunostaining}

Immunostaining was evaluated by light microscopy blindly and independently by GPB and ISB, and a consensus agreement was achieved. Cyclooxygenase type- 2 expression was scored 0 (absent), $1+$ (weak), $2+$ (moderate) and $3+$ (strong) based on the extent and intensity of epithelial cell staining (Half et al, 2002; Ristimaki et al, 2002; Shim et al, 2003). Cyclooxygenase type-2 positivity was defined as a score $\geqslant 2$ (Shamma et al, 2000; Ristimaki et al, 2002; Shim et al, 2003). HER-2 staining was scored 0 (absent) to 3 (maximum cyto-membranous staining seen, comparable to a $3+$ positive invasive cancer control), with a score $\geqslant 2$ considered HER-2 positive (Birner et al, 2001). Ki67 and ER scores were calculated as the percentage of positively stained nuclei. Oestrogen receptor positivity was defined as $\geqslant 5 \%$ stained nuclei, and has been used in previous studies in DCIS in our unit (Holland et al, 1997; Gandhi et al, 1998, 2000; Boland et al, 2003b). For each section, a minimum of 1000 cells were scored across randomly selected areas of DCIS at a magnification of $\times 400$ using a grid graticule and cell counter.

\section{Statistical analysis}

Cyclooxygenase type-2 expression scores between different breast tissues were compared using the Mann-Whitney test. The relationship between categorical variables was analysed using the $\chi^{2}$ test and the association of categorical variables with continuous variables analysed using the Kruskal-Wallis and Mann-Whitney tests. Significance tests were two-tailed and a significance level of $5 \%$ was used throughout.

\section{RESULTS}

\section{COX-2 immunostaining in different breast tissues}

Cyclooxygenase type-2 immunostaining was determined in 372 samples of normal and neoplastic breast ductal epithelium (Table 1, Figure 1). In all cases, positive cellular immunostaining was cytoplasmic. Strong immunoreactivity was also observed in the smooth muscle of the tunica media of blood vessels and in the myoepithelial cells surrounding neoplastic breast ducts. No immunoreactivity was seen in stromal cells or in vasculature around normal breast ductules.

Cyclooxygenase type- 2 expression in pure DCIS $(n=187)$ and IBC $(n=65)$ was significantly higher than in normal breast tissue (either from breast reduction tissue, $n=60$ or from ducts surrounding DCIS, $n=60, P<0.0001$, Mann - Whitney test). There was, however, no difference in the median COX-2 expression between in situ and invasive cancer $(P=0.59)$, or between normal tissue from breast reduction samples and normal ducts around 
Table I COX-2 expression in normal and neoplastic breast

COX-2 score $(0=$ absent to $3=$ maximum $)$

\begin{tabular}{|c|c|c|c|c|c|c|c|}
\hline Tissue & No. & 0 & $\mathbf{I}$ & 2 & 3 & No. COX-2 +ve (score $\geqslant 2+)$ & $P$-value ${ }^{b}$ \\
\hline NB around DCIS & 60 & $33(55 \%)$ & $14(23 \%)$ & $9(15 \%)$ & $4(7 \%)$ & $13 / 60(22 \%)$ & 0.29 \\
\hline
\end{tabular}

NB was from breast reduction tissue and ducts surrounding DCIS. Cyclooxygenase type-2 expression was scored 0 (absent) to 3 (maximum intensity seen) on tissue sections from each patient, with a score $\geqslant 2$ considered COX-2 expression positive. The P-values (Mann-Whitney test) are for comparison to COX-2 expression in NB from breast reduction tissue (Referent). COX-2 = cyclooxygenase type-2; $\mathrm{NB}=$ normal breast; $\mathrm{DCIS}=$ ductal carcinoma in situ. ${ }^{\mathrm{a}} \mathrm{DClS}$ nuclear grade. ${ }^{\mathrm{b}}$ Mann - Whitney test.

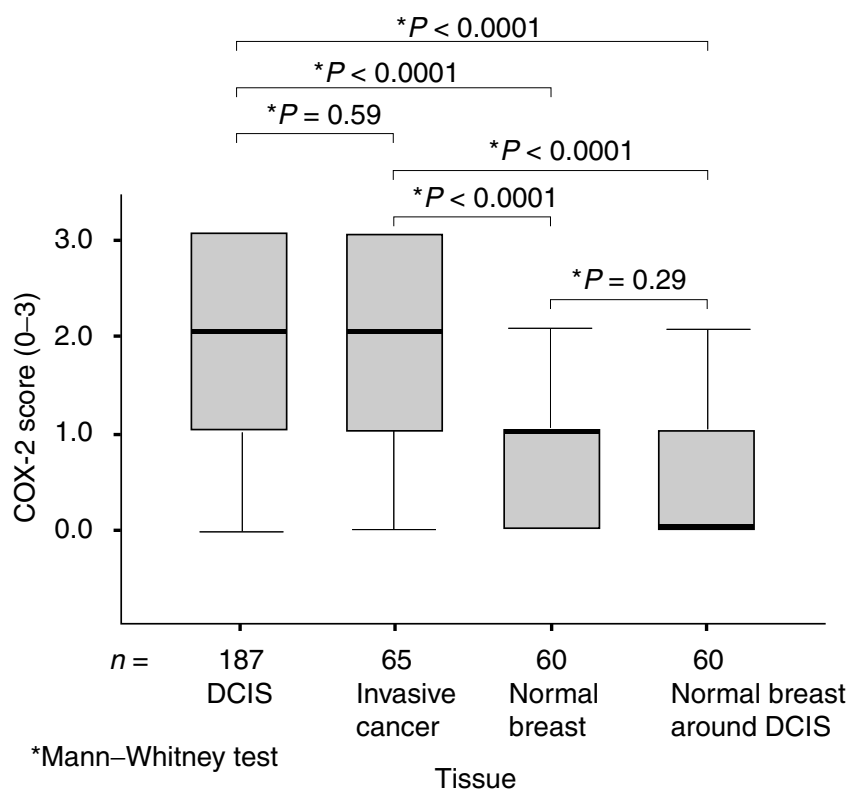

Figure I COX-2 expression in normal and neoplastic breast tissue. For each tissue, the thick black horizontal bars represent the median COX-2 score, the boxes represent the interquartile range and the T-bars the full range. The median COX-2 expression in neoplastic DCIS and invasive cancer epithelium are significantly greater than in normal breast ducts $(P<0.000 \mathrm{I})$, although there was no difference between DCIS and invasive cancer in median expression $(P=0.59)$

DCIS $(P=0.29)$. The percentage of COX-2 positivity (a staining score $\geqslant 2+)$ for DCIS, invasive cancer and normal breast from reduction and around DCIS was $67,63,23$ and 22 , respectively. Comparable COX-2 Immunoreactivity was confirmed in DCIS with a different COX-2 primary antibody from the Cayman Chemical Company (Ann Arbor, MI, USA, 160112) in 50 DCIS sections.

\section{COX-2 expression in DCIS and other clinico-pathological parameters}

In DCIS, there was no association between COX-2 expression and patient age above and below the age of 50 years $(P=0.34$, Table 2$)$. Cyclooxygenase type- 2 expression increased significantly with increasing nuclear grade $(P=0.003)$, with the largest difference
Table 2 COX-2 expression and clinicopathological parameters in women with DCIS $(n=187)$ and IBC $(n=65)$

\begin{tabular}{|c|c|c|c|}
\hline Parameter & Number & $\%$ COX-2 +ve & $P$-value ${ }^{a}$ \\
\hline \multicolumn{4}{|l|}{ DCIS } \\
\hline \multicolumn{4}{|l|}{ Age (years) } \\
\hline $\begin{array}{l}<50 \\
\geqslant 50\end{array}$ & $\begin{array}{r}35 \\
152\end{array}$ & $\begin{array}{l}62 \% \\
69 \%\end{array}$ & 0.34 \\
\hline \multicolumn{4}{|l|}{ Nuclear grade } \\
\hline Low & 27 & $44 \%$ & \\
\hline Intermediate & 64 & $64 \%$ & 0.003 \\
\hline High & 96 & $75 \%$ & \\
\hline \multicolumn{4}{|l|}{ ER status } \\
\hline Positive & 111 & $58 \%$ & 0.003 \\
\hline Negative & 75 & $80 \%$ & \\
\hline \multicolumn{4}{|c|}{ Ki67 cell proliferation } \\
\hline$<10 \%$ & 93 & $55 \%$ & $<0.0001$ \\
\hline$\geqslant 10 \%$ & 90 & $79 \%$ & \\
\hline \multicolumn{4}{|l|}{ HER-2 status } \\
\hline Positive & 102 & $82 \%$ & $<0.0001$ \\
\hline Negative & 85 & $48 \%$ & \\
\hline \multicolumn{4}{|c|}{ Invasive cancer } \\
\hline \multicolumn{4}{|c|}{ Age (years) } \\
\hline$<50$ & 23 & $64 \%$ & 0.67 \\
\hline$\geqslant 50$ & 42 & $62 \%$ & \\
\hline \multicolumn{4}{|l|}{ Nuclear grade } \\
\hline I & 17 & $53 \%$ & \\
\hline ॥ & 17 & $58 \%$ & 0.43 \\
\hline III & 21 & $71 \%$ & \\
\hline \multicolumn{4}{|l|}{ ER status } \\
\hline Positive & 40 & $50 \%$ & 0.005 \\
\hline Negative & 25 & $84 \%$ & \\
\hline \multicolumn{4}{|c|}{ Ki67 cell proliferation } \\
\hline$<10 \%$ & 29 & $50 \%$ & 0.04 \\
\hline$\geqslant 10 \%$ & 36 & $74 \%$ & \\
\hline \multicolumn{4}{|l|}{ HER-2 status } \\
\hline Positive & 29 & $79 \%$ & 0.014 \\
\hline Negative & 36 & $50 \%$ & \\
\hline
\end{tabular}

Age above and below 50 years was used to separate pre- and postmenopausal patients crudely. Oestrogen receptor positivity was a tumour with $\geqslant 5 \%$ nuclei expressing the ER receptor for both DCIS and IBC. A comparison of COX-2 positivity with Ki67 cell proliferation above and below 10\% was used because the median DCIS cell proliferation was approximately 10\%. HER-2 positivity was an immunostaining score of $\geqslant 2+$ (reference laboratory standard). Categorical variables were compared differences using the $\chi^{2}$ test. COX-2 = cyclooxygenase type-2; $\mathrm{DCIS}=$ ductal carcinoma in situ; $\mathrm{IBC}=$ invasive breast cancer; $\mathrm{ER}=$ oestrogen receptor. ${ }^{\mathrm{a}} \chi^{2}$ test. 
A

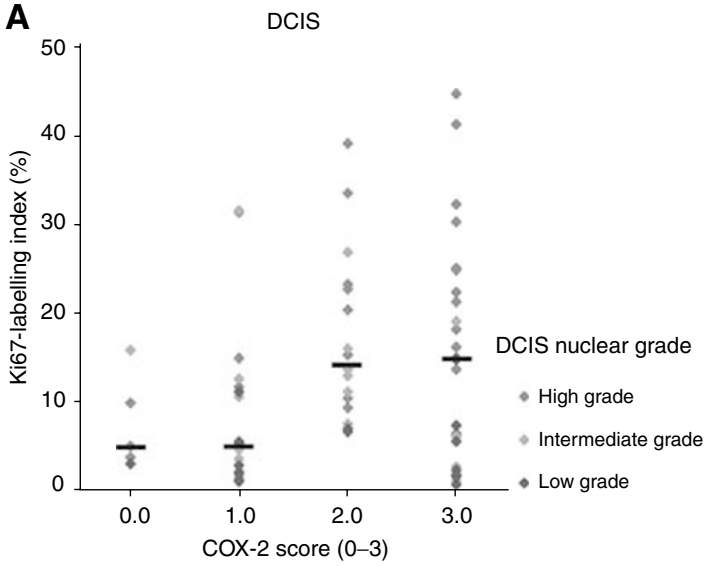

B Invasive breast cancer

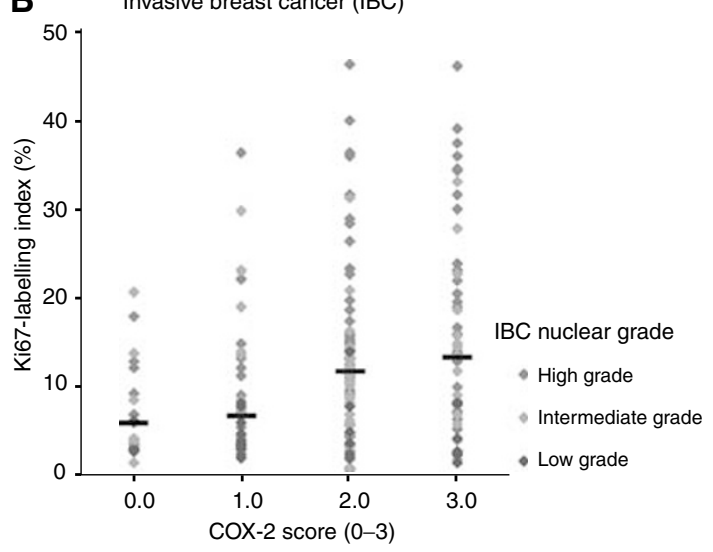

C Normal breast (reduction)

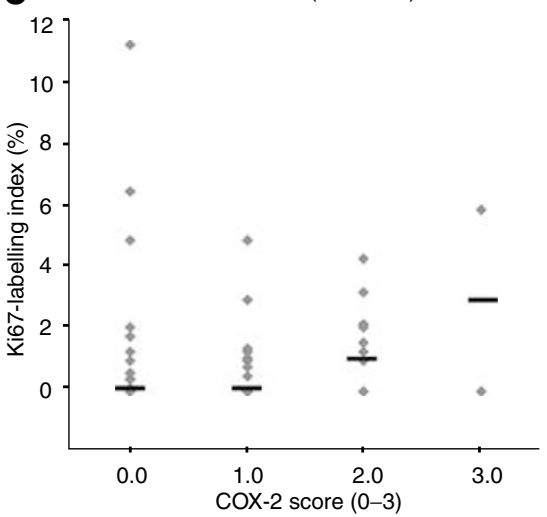

D Normal breast around DCIS

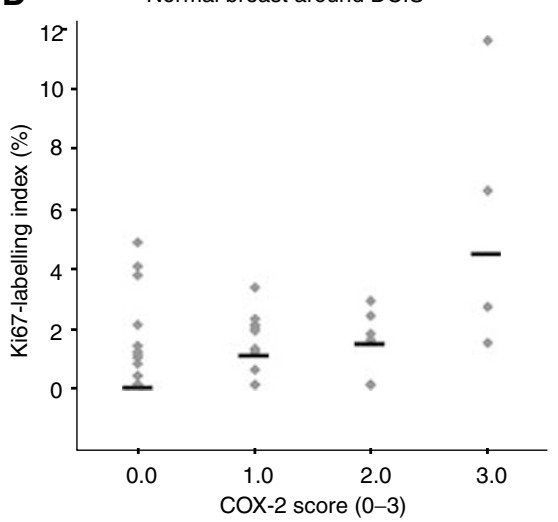

between intermediate (64\% positivity) and high-grade (75\% positivity) DCIS lesions compared to low-grade DCIS lesions (44\% positivity, Table 2, Figure 2). Similarly, there was a positive association of COX-2 immunoreactivity with cell proliferation in DCIS $(P=0.004$, Kruskal-Wallis test, Figure 2$)$. The group of DCIS tumours with a ki67 cell proliferation of $\geqslant 10 \%(n=90)$ was associated with $79 \%$ COX-2 positivity compared to $55 \%$ in the group with $<10 \%(n=93)$ of cell expressing the Ki67 antigen $\left(P<0.0001, \chi^{2}\right.$ test, Table 2$)$. There was a significant association between ER negativity (40\% of DCIS) and COX-2 positivity, with $80 \%$ of ER-negative DCIS showing COX-2 positivity compared to $58 \%$ of ER-positive DCIS tumours $\left(P=0.003, \chi^{2}\right.$ test, Table 2$)$. The overall HER-2 positivity rate for DCIS tumours selected for this series was $55 \%$. Cyclooxygenase type-2 positivity was significantly higher in HER-2-positive DCIS tumours (82\%) than HER-2negative tumours ( $48 \%, P<0.0001$, Table 2 , Figure 3 ).

\section{COX-2 expression in IBC and other clinco-pathological parameters}

There was no significant association between COX-2 expression in IBC with patient age or with nuclear grade, although the percentage of COX-2 positivity was greater in high-grade compared to non-high-grade tumours (Table 2, Figure 2). Similar to DCIS, there was an association between COX-2 expression in IBC with a higher cell proliferation (Ki67, $P=0.04, \chi^{2}$ test), HER-2 positivity $(P=0.014)$ and with ER negativity $(P=0.005)$.

\section{COX-2 expression and cell proliferation in normal breast}

Although the median cell proliferation was lower in normal breast compared to in situ and invasive cancer, there was a significant association between increasing cell proliferation and COX-2 expression in normal breast ductal epithelium in both reduction mammoplasty tissue $(P=0.03$, Mann-Whitney test) and from around DCIS $(P=0.004$, Figure 2$)$.

\section{DISCUSSION}

Cyclooxygenase type- 2 is overexpressed along the continuum of carcinogenesis from preinvasive lesions to metastatic disease in tissues of both squamous and glandular origin (Eberhart et al, 1994; Kirschenbaum et al, 2000; Shirahama, 2000; Soslow et al, 2000; Morris et al, 2001; Costa et al, 2002). Cyclooxygenase type-2 overexpression in IBCs is associated with unfavourable prognostic indices (Ristimaki et al, 2002; Denkert et al, 2003; Spizzo et al, 2003). Evidence from both human and animal studies strongly suggests that cancer can be prevented by COX-2 inhibition.

This is the largest study to demonstrate elevated COX-2 expression in pure DCIS and has shown COX-2 overexpression in both in situ and IBC compared with normal breast. Since most IBC is believed to originate from DCIS (the two coexist in about $50 \%$ of cases), the inhibition of COX-2 represents a potential target for preventing breast cancer oncogenesis and as an adjuvant treatment following surgery to reduce local recurrence.

In this study, COX-2 expression was determined using immunohistochemistry on archival samples of breast tissue using

Figure 2 Association between COX-2 expression score and cell proliferation (Ki67-labelling index) for DCIS, IBC and normal breast. For DCIS and IBC, individual ki67 scores are separated by nuclear grade. The thick black horizontal lines represent the median Ki67 score for each COX2 score $(0-3)$ for each tissue. For each tissue type, there is a significant increase in Ki67 with increasing COX-2 score. In DCIS and IBC, the median Ki67 increases with increasing nuclear grade, although this is only significant for DCIS $(P=0.003)$. 

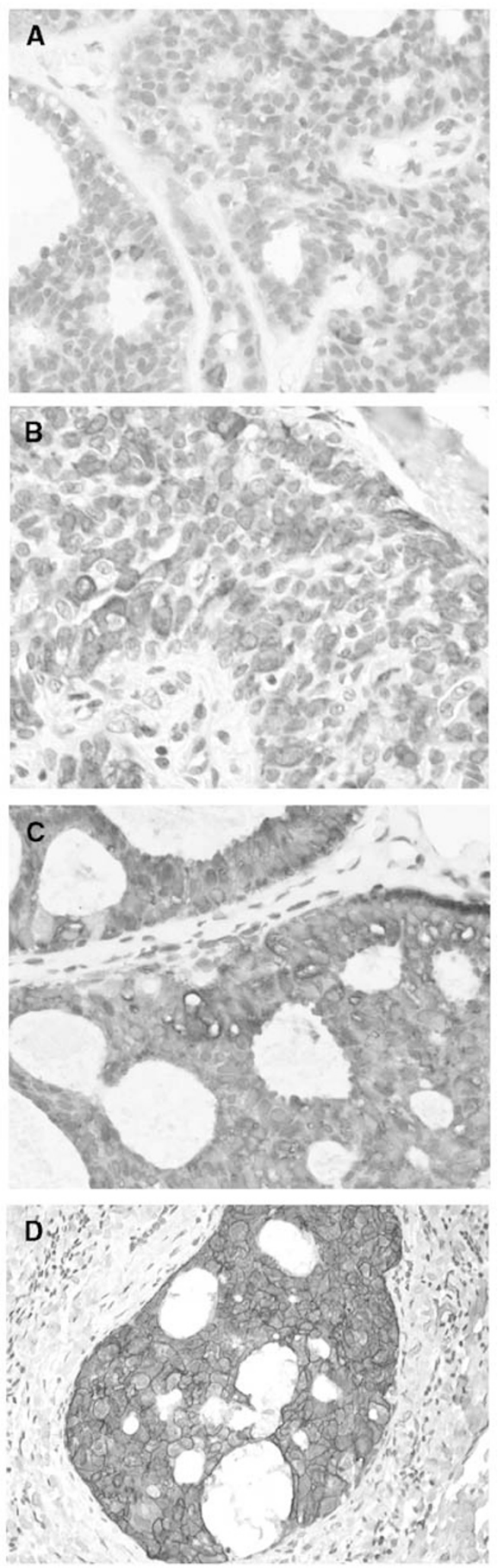

Figure 3 (A) DCIS showing minimal COX-2 expression with scanty brown cytoplasmic immunostaining (score $1+$, classified as COX-2 negative), (B) moderate COX-2 staining with approximately 5060\% of cells strongly stained (score $2+$, classified as COX-2 positive), (C) High COX-2 expression in cribriform DCIS with 100\% of cells intensely stained (score $3+$, classified as COX-2 positive), (D) HER-2 staining in DCIS: note the strong membranous staining (score $3+$, classified HER-2 positive). scoring systems reported by others (Half et al, 2002; Ristimaki et al, 2002). Overall, COX-2 overexpression was demonstrated in $67 \%$ of DCIS and $63 \%$ of invasive tumours. For DCIS, this is consistent with the studies that have reported COX-2 in DCIS tumours (Soslow et al, 2000; Half et al, 2002; Shim et al, 2003; Watanabe et al, 2003).

The few published data with regard to COX-2 expression in normal breast tissue are conflicting. Using RT-PCR, Half et al (2002) reported a lower COX-2 mRNA level in normal breast tissue than in paired neoplastic tissue in eight of nine samples, while Watanabe et al (2003) found no COX-2 mRNA in normal breast tissue examined. Costa et al (2002) reported COX-2 protein expression in eight of 46 IBCs using Western immunoblotting, but found no COX-2 antigen in the adjacent normal tissue samples studied. This discrepancy can be partly explained by the paucity of ductal units in 'normal breast' (mostly stromal tissue in which COX-2 is not expressed) in comparison to neoplastic tissue.

By immunohistochemistry, COX-2 expression has been reported in normal breast ductules surrounding non-low-grade DCIS at levels equal $(15 \%)$ or higher $(85 \%)$ than in the index neoplastic lesion (Shim et al, 2003), although immuno-positivity decreases with distance. A similar finding was reported by Half and colleagues with expression in $81 \%$ of 48 samples, although they found staining to be focal and generally similar or decreased in intensity relative to adjacent neoplastic epithelia (Half et al, 2002). Watanabe et al (2003) reported a low level of COX-2 expression in $50 \%$ of normal epithelia surrounding DCIS, but in only $15 \%$ of normal epithelia surrounding invasive disease. This is confirms the findings of Soslow et al (2000), who reported expression in only three out of (17\%) of normal breast tissue close to invasive cancer.

We demonstrated COX-2 immunoreactivity in $45 \%$ of normal breast adjacent to DCIS, consistent with the findings of Wanatabe et al, but we only scored this as COX-2 positive in $22 \%$ of cases. However, the normal ductules examined in the present study were on tissue sections taken from blocks of normal tissue harvested macroscopically close to the neoplastic tissue (not necessarily on ducts directly adjacent to the neoplastic lesion), which in reality may be up to $2 \mathrm{~cm}$ distal to the margin of the index neoplastic lesion. This may explain why our COX-2 positivity in adjacent normal breast is lower than that reported by others. We did not report expression in normal ducts surrounding invasive cancer. The present study is the first to report COX-2 expression in normal breast from reduction mammoplasty tissue. We found immunoreactivity in $58 \%$ of samples, but only scored this as COX-2 positive in $23 \%$, which is not statistically different from the expression in normal ducts surrounding DCIS $(P=0.29)$.

The COX-2 positivity (63\%) rate in IBCs in this study is higher than in other studies (Soslow et al, 2000; Half et al, 2002; Ristimaki et al, 2002; Spizzo et al, 2003; Watanabe et al, 2003), which have reported expression in $36-56 \%$ of tumours. This disparity can be explained by the deliberate selection of HER-2-positive invasive tumours in this study (45\%), chosen to compare COX-2 expression between HER-2-expressing and non-HER-2-expressing cancers. HER-2 is overexpressed in approximately $20-30 \%$ of IBCs (and therefore lower overall than in this study), and is an independent marker of poor prognostic disease (Tsutsui et al, 2002). An association between HER-2 and COX-2 expression in IBC has been reported in cell line (Vadlamudi et al, 1999; Subbaramaiah et al, 2002b), animal (Howe et al, 2002) and in human immunohistochemical studies (Ristimaki et al, 2002). Ristimaki et al (2002) found a higher COX-2 expression in HER-2-expressing breast cancer; the present study confirmed this association. Furthermore, dual drug blockade of COX-2 and HER-2 in cancer cell lines expressing both oncogenes has been shown to reduce cell growth more effectively than the inhibition by one of the agents alone (Mann et al, 2001). These studies suggest that signalling through the HER-2 receptor may have a role in modulating the upregulation of COX-2 in IBC. 
Since HER-2 overexpression is reported in up to $80 \%$ of DCIS tumours and is associated with high-grade phenotype (Allred et al, 1993; Bobrow et al, 1995; Suo et al, 2001), we investigated the association of COX-2 and HER-2 expression in DCIS. The overall HER-2 positivity rate for DCIS in this study was only $55 \%$, reflecting the deliberate inclusion of a higher proportion of non-high-grade DCIS tumours in this study (associated with a lower HER-2 positivity) to investigate COX-2 expression across nuclear grades. Consistent with the findings in invasive tumours, we found that COX-2 positivity was significantly higher in HER-2-positive DCIS (82\%) than in HER-2-negative DCIS (48\%). Importantly, this finding in in situ breast cancer confirms the association of the HER-2 receptor with COX-2 overexpression reported in breast cancer cell line studies (Vadlamudi et al, 1999; Subbaramaiah et al, 2002a) (and by immunohistochemistry; Ristimaki et al, 2002), which suggest that signalling through HER-2/Ras/Map kinase pathway may play a role in upregulating COX-2 in neoplasia and this may occur at the preinvasive stage of breast cancer carcinogenesis. This could explain why COX-2 expression is higher in DCIS than IBC.

Inhibition of the COX-2 enzyme and attenuation of the consequential carcinogenic effects of overexpression with increased prostaglandin production (inhibition of apoptosis, stimulation of neo-angiogenesis, upregulation of intra-tumoral CYP19 aromatase; Davies et $a l, 2002)$ at this stage has the potential to prevent progression to invasion.

In DCIS tumours, we also found COX-2 expression to be positively associated with higher cellular proliferation rates, higher nuclear grade and with ER negativity. These findings, together with the association of COX-2 with HER-2 expression, are consistent with those reported in IBC (Ristimaki et al, 2002). This is important since these factors are surrogate markers of an aggressive DCIS phenotype and link nonoestrogen growth factor signalling pathways with COX-2 overexpression. The association of COX-2 expression with nuclear grade in DCIS confirms the findings of Shim et al (2003). Since nuclear grade is an independent marker of DCIS local recurrence (Silverstein et al, 1996; Boland et al, 2003a), further study is warranted to determine whether COX-2 is independent of grade with regard to the risk local DCIS recurrence following breast conservation.

These findings may have important therapeutic and cancer chemo-preventative implications. Since signalling through HER-2 pathways is believed to be involved in driving cell proliferation in ER-negative IBC and to resist anti-oestrogen therapy in ERexpressing/HER-2-positive cancers, the association of COX-2 with HER-2 expression in DCIS suggests that the carcinogenic sequalae of COX-2 overexpression originate at the preinvasive stage in breast carcinogenesis.

There is a clinical need to determine whether women with HER2-positive/COX-2-positive DCIS represent a high-risk patient population for disease progression or local recurrence; this cohort especially may benefit form COX-2 inhibitor therapy. Phase II clinical trials are presently in progress to determine the efficacy of COX-2 inhibition combined with Herceptin in HER-expressing metastatic breast cancer.

The targeting of nonhormonal pathways will be necessary to prevent both ER-positive and ER-negative breast cancer. Since COX-2 inhibition is a relatively safe therapeutic option, we believe that prospective clinical trials are warranted to determine the clinical benefit of long-term COX-2 inhibition in preventing breast cancer and as an adjuvant therapy after DCIS treatment.

\section{REFERENCES}

Allred DC, O’Connell P, Fuqua SA (1993) Biomarkers in early breast neoplasia. J Cell Biochem 17G(Suppl): 125-131

Alshafie GA, Abou-Issa HM, Seibert K, Harris RE (2000) Chemotherapeutic evaluation of Celecoxib, a cyclooxygenase- 2 inhibitor, in a rat mammary tumor model. Oncol Rep 7: 1377-1381

Birner P, Oberhuber G, Stani J, Reithofer C, Samonigg H, Hausmaninger H, Kubista E, Kwasny W, Kandioler-Eckersberger D, Gnant M, Jakesz R (2001) Evaluation of the United States Food and Drug Administration approved scoring and test system of HER-2 protein expression in breast cancer. Clin Cancer Res 7: 1669-1675

Bobrow LG, Happerfield LC, Gregory WM, Millis RR (1995) Ductal carcinoma in situ: assessment of necrosis and nuclear morphology and their association with biological markers. J Pathol 176: 333-341

Boland GP, Chan KC, Knox WF, Roberts SA, Bundred NJ (2003a) Value of the Van Nuys Prognostic Index in prediction of recurrence of ductal carcinoma in situ after breast-conserving surgery. Br J Surg 90: 426-432

Boland GP, Mckeown A, Chan KC, Prasad R, Knox WF, Bundred NJ (2003b) Biological response to hormonal manipulation in oestrogen receptor positive ductal carcinoma in situ of the breast. Br J Cancer 89: $227-283$

Cianchi F, Cortesini C, Bechi P, Fantappie O, Messerini L, Vannacci A, Sardi I, Baroni G, Boddi V, Mazzanti R, Masini E (2001) Up-regulation of cyclooxygenase 2 gene expression correlates with tumor angiogenesis in human colorectal cancer. Gastroenterology 121: 1339-1347

Costa C, Soares R, Reis-Filho JS, Leitao D, Amendoeira I, Schmitt FC (2002) Cyclo-oxygenase 2 expression is associated with angiogenesis and lymph node metastasis in human breast cancer. J Clin Pathol 55: 429-434

Davies G, Martin LA, Sacks N, Dowsett M (2002) Cyclooxygenase-2 (COX2 ), aromatase and breast cancer: a possible role for COX-2 inhibitors in breast cancer chemoprevention. Ann Oncol 13: 669-678

Denkert C, Winzer K-J, Muller B-M, Weichert W, Pest S, Kobel M, Kristiansen G, Reles A, Siegert A, Guski H, Hauptmann S (2003) Elevated expression of cyclooxygenase- 2 is a negative prognostic factor for disease survival and overall survival in patients with breast cancer. Cancer 97: $2978-2987$
Dowsett M, Bundred NJ, Decensi A, Sainsbury RC, Lu Y, Hills MJ, Cohen FJ, Veronesi P, O’Brien ME, Scott T, Muchmore DB (2001) Effect of raloxifene on breast cancer cell $\mathrm{Ki} 67$ and apoptosis: a double-blind, placebo-controlled, randomized clinical trial in postmenopausal patients. Cancer Epidemiol Biomarkers Prev 10: $961-966$

Eberhart CE, Coffey RJ, Radhika A, Giardiello FM, Ferrenbach S, DuBois RN (1994) Up-regulation of cyclooxygenase 2 gene expression in human colorectal adenomas and adenocarcinomas. Gastroenterology 107: 1183 1188

Gandhi A, Holland PA, Knox WF, Potten CS, Bundred NJ (1998) Evidence of significant apoptosis in poorly differentiated ductal carcinoma in situ of the breast. Br J Cancer 78: 788-794

Gandhi A, Holland PA, Knox WF, Potten CS, Bundred NJ (2000) Effects of a pure antiestrogen on apoptosis and proliferation within human breast ductal carcinoma in situ. Cancer Res 60: 4284-4288

Half E, Tang XM, Gwyn K, Sahin A, Wathen K, Sinicrope FA (2002) Cyclooxygenase-2 expression in human breast cancers and adjacent ductal carcinoma in situ. Cancer Res 62: 1676-1681

Harris RE, Alshafie GA, Abou-Issa H, Seibert K (2000) Chemoprevention of breast cancer in rats by celecoxib, a cyclooxygenase 2 inhibitor. Cancer Res 60: $2101-2103$

Hasturk S, Kemp B, Kalapurakal SK, Kurie JM, Hong WK, Lee JS (2002) Expression of cyclooxygenase-1 and cyclooxygenase-2 in bronchial epithelium and nonsmall cell lung carcinoma. Cancer 94: 1023-1031

Holland PA, Knox WF, Potten CS, Howell A, Anderson E, Baildam AD, Bundred NJ (1997) Assessment of hormone dependence of comedo ductal carcinoma in situ of the breast. J Natl Cancer Inst 89: 1059-1065

Howe LR, Subbaramaiah K, Patel J, Masferrer JL, Deora A, Hudis C, Thaler HT, Muller WJ, Du B, Brown AM, Dannenberg AJ (2002) Celecoxib, a selective cyclooxygenase 2 inhibitor, protects against human epidermal growth factor receptor 2 (HER-2)/neu-induced breast cancer. Cancer Res 62: $5405-5407$

Hwang D, Scollard D, Byrne J, Levine E (1998) Expression of cyclooxygenase- 1 and cyclooxygenase- 2 in human breast cancer. $J$ Natl Cancer Inst 90: $455-460$ 
Khuder SA, Mutgi AB (2001) Breast cancer and NSAID use: a meta-analysis. Br J Cancer 84: 1188-1192

Kirschenbaum A, Klausner AP, Lee R, Unger P, Yao S, Liu XH, Levine AC (2000) Expression of cyclooxygenase-1 and cyclooxygenase-2 in the human prostate. Urology 56: $671-676$

Komhoff M, Guan Y, Shappell HW, Davis L, Jack G, Shyr Y, Koch MO, Shappell SB, Breyer MD (2000) Enhanced expression of cyclooxygenase-2 in high grade human transitional cell bladder carcinomas. Am J Pathol 157: $29-35$

Kundu N, Fulton AM (2002) Selective cyclooxygenase (COX)-1 or COX-2 inhibitors control metastatic disease in a murine model of breast cancer. Cancer Res 62: 2343-2346

Liu CH, Chang SH, Narko K, Trifan OC, Wu MT, Smith E, Haudenschild C, Lane TF, Hla T (2001) Overexpression of cyclooxygenase-2 is sufficient to induce tumorigenesis in transgenic mice. J Biol Chem 276: 1856318569

Mann M, Sheng H, Shao J, Williams CS, Pisacane PI, Sliwkowski MX, DuBois RN (2001) Targeting cyclooxygenase 2 and HER-2/neu pathways inhibits colorectal carcinoma growth. Gastroenterology 120: $1713-1719$

Mohammed SI, Knapp DW, Bostwick DG, Foster RS, Khan KN, Masferrer JL, Woerner BM, Snyder PW, Koki AT (1999) Expression of cyclooxygenase-2 (COX-2) in human invasive transitional cell carcinoma (TCC) of the urinary bladder. Cancer Res 59: 5647-5650

Morris CD, Armstrong GR, Bigley G, Green H, Attwood SE (2001) Cyclooxygenase-2 expression in the Barrett's metaplasia-dysplasiaadenocarcinoma sequence. Am J Gastroenterol 96: 990-996

Muller-Decker K, Neufang G, Berger I, Neumann M, Marks F, Furstenberger G (2002) Transgenic cylclooxygenase-2 overexpression sensitizes mouse skin for carcinogenesis. Proc Natl Acad Sci USA 99: 12483-12488

Parrett ML, Harris RE, Joarder FS, Ross MS, Clausen KP, Robertson FM (1997) Cyclooxygenase-2 expression in human breast cancer. Int J Oncol 10: $503-507$

Ristimaki A, Nieminen O, Saukkonen K, Hotakainen K, Nordling S, Haglund C (2001) Expression of cyclooxygenase-2 in human transitional cell carcinoma of the urinary bladder. Am J Pathol 158: 849-853

Ristimaki A, Sivula A, Lundin J, Lundin M, Salminen T, Haglund C, Joensuu H, Isola J (2002) Prognostic significance of elevated cyclooxygenase-2 expression in breast cancer. Cancer Res 62: 632-635

Rozic JG, Chakraborty C, Lala PK (2001) Cyclooxygenase inhibitors retard murine mammary tumor progression by reducing tumor cell migration, invasiveness and angiogenesis. Int J Cancer 93: 497-506

Sales KJ, Katz AA, Davis M, Hinz S, Soeters RP, Hofmeyr MD, Millar RP, Jabbour HN (2001) Cyclooxygenase-2 expression and prostaglandin $\mathrm{E}(2)$ synthesis are up- regulated in carcinomas of the cervix: a possible autocrine/paracrine regulation of neoplastic cell function via EP2/EP4 receptors. J Clin Endocrinol Metab 86: 2243-2249

Sano H, Kawahito Y, Wilder RL, Hashiramoto A, Mukai S, Asai K, Kimura S, Kato H, Kondo M, Hla T (1995) Expression of cyclooxygenase-1 and -2 in human colorectal cancer. Cancer Res 55: $3785-3789$

Shaheen NJ, Straus WL, Sandler RS (2002) Chemoprevention of gastrointestinal malignancies with nonsteroidal antiinflammatory drugs. Cancer 94: 950-963

Shamma A, Yamamoto H, Doki Y, Okami J, Kondo M, Fujiwara Y, Yano M, Inoue M, Matsuura N, Shiozaki H, Monden M (2000) Up-regulation of cyclooxygenase-2 in squamous carcinogenesis of the esophagus. Clin Cancer Res 6: 1229-1238
Shim V, Gauthier ML, Sudilovsky D, Mantei K, Chew KL, Moore DH, Cha I, Tlsty TD, Esserman LJ (2003) Cyclooxygenase-2 expression is related to nuclear grade in ductal carcinoma in situ and is increased in its normal adjacent epithelium. Cancer Res 63: 2347-2350

Shirahama T (2000) Cyclooxygenase-2 expression is up-regulated in transitional cell carcinoma and its preneoplastic lesions in the human urinary bladder. Clin Cancer Res 6: 2424-2430

Shirahama T, Arima J, Akiba S, Sakakura C (2001) Relation between cyclooxygenase-2 expression and tumor invasiveness and patient survival in transitional cell carcinoma of the urinary bladder. Cancer 92: $188-193$

Silverstein MJ, Lagios MD, Craig PH, Waisman JR, Lewinsky BS, Colburn WJ, Poller DN (1996) A prognostic index for ductal carcinoma in situ of the breast. Cancer 77: 2267-2274

Soslow RA, Dannenberg AJ, Rush D, Woerner BM, Khan KN, Masferrer J, Koki AT (2000) COX-2 is expressed in human pulmonary, colonic, and mammary tumors. Cancer 89: 2637-2645

Spizzo G, Gastl G, Wolf D, Gunsilius E, Steurer M, Fong D, Amberger A, Margreiter R, Obrist P (2003) Correlation of COX-2 and Ep-CAM overexpression in human invasive breast cancer and its impact on survival. Br I Cancer 88: 574-578

Subbaramaiah K, Norton L, Gerald W, Dannenberg AJ (2002a) Cyclooxygenase-2 is overexpressed in HER-2/neu-positive breast cancer: evidence for involvement of AP-1 and PEA3. J Biol Chem 277: 1864918657

Subbaramaiah K, Norton L, Gerald W, Dannenberg AJ (2002b) Cyclooxygenase-2 is overexpressed in HER-2/neu-positive breast cancer: evidence for involvement of AP-1 and PEA3. J Biol Chem 277: 1864918657

Suo Z, Bjaamer A, Ottestad L, Nesland JM (2001) Expression of EGFR family and steroid hormone receptors in ductal carcinoma in situ of the breast. Ultrastruct Pathol 25: 349-356

Tsujii M, DuBois RN (1995) Alterations in cellular adhesion and apoptosis in epithelial cells overexpressing prostaglandin endoperoxide synthase 2. Cell 83: $493-501$

Tsujii M, Kawano S, DuBois RN (1997) Cyclooxygenase-2 expression in human colon cancer cells increases metastatic potential. Proc Natl Acad Sci USA 94: 3336-3340

Tsujii M, Kawano S, Tsuji S, Sawaoka H, Hori M, DuBois RN (1998) Cyclooxygenase regulates angiogenesis induced by colon cancer cells. Cell 93: 705-716

Tsutsui S, Ohno S, Murakami S, Hachitanda Y, Oda S (2002) Prognostic value of c-erbB2 expression in breast cancer. J Surg Oncol 79: 216-223

Tucker ON, Dannenberg AJ, Yang EK, Zhang F, Teng L, Daly JM, Soslow RA, Masferrer JL, Woerner BM, Koki AT, Fahey III TJ (1999) Cyclooxygenase-2 expression is up-regulated in human pancreatic cancer. Cancer Res 59: $987-990$

Vadlamudi R, Mandal M, Adam L, Steinbach G, Mendelsohn J, Kumar R (1999) Regulation of cyclooxygenase-2 pathway by HER2 receptor. Oncogene 18: 305-314

Watanabe O, Shimizu T, Kinoshita J, Utada Y, Okabe T, Kimura K, Hirano A, Yoshimatsu K, Aiba M, Ogawa K (2003) Expression of cyclooxygenase-2 in malignant and benign breast tumours. Anticancer Res 23: 3215 3221

Wolff H, Saukkonen K, Anttila S, Karjalainen A, Vainio H, Ristimaki A (1998) Expression of cyclooxygenase-2 in human lung carcinoma. Cancer Res 58: $4997-5001$ 